\title{
ESPORTES NA TERCEIRA IDADE: Os benefícios para a longevidade.
}

\author{
ESPORTE E LONGEVIDADE
}

'Bruno Freitas Santos

\section{RESUMO}

INTRODUÇÃO: A população idosa é crescente no Brasil, e isso significa que é necessário cuidar desse público tão importante, traçando metas e construindo políticas públicas que os contemplem. Uma das soluções é a prática de exercícios físicos para amenizar tantos problemas de saúde e disponibilizar uma maior qualidade de vida. OBJETIVO: o objetivo central é estimular a reflexão sobre a relevância, que as práticas esportivas podem trazer para o público da terceira idade, devolvendo um novo sentido para viver de forma mais prazerosa e ativa. MÉTODO: Baseado em trabalhos teóricos de Balbinotti (2014), Cavalcanti (1997), Barroso (2002) e outros; a metodologia utilizada foi por meio de fonte bibliográfica, tendo como instrumentos a pesquisa também bibliográfica, mostrando que o esporte e as práticas físicas, podem e devem ser um recurso importante para a construção de uma vida muito mais ativa e saudável. Inicialmente, foi feita uma revisão bibliográfica para compreender com maior propriedade processo de envelhecimento, e como envelhecer e manter-se saudável. RESULTADOS: Os resultados desta pesquisa visam verificar a relevância das práticas esportivas para uma vida mais saudável e prazerosa. CONCLUSÃO: Conclui-se que é notório a percepção que há um número pequeno de pessoas idosas, que adotam um estilo de vida ativo e esportivo, e que é preciso estimular e conscientizar, acerca da importância das atividades físicas para o corpo e para a mente.

Palavras-chave: Idosos; Saúde; Práticas Físicas.

\section{SPORTS IN THE ELDERLY: the benefits to longevity.}

\section{ABSTRACT}

Introduction: the elderly population is growing in Brazil, and this means that it is necessary to care for this important public, setting goals and building public policies that contemplate them. one of the solutions is the practice of physical exercises to alleviate so many health problems and provide a higher quality of life. Objective: the central objective is to stimulate reflection on the relevance that sports practices can bring to the elderly, giving a new meaning to live in a more pleasurable and active way. Method: based on theoretical works of balbinotti (2014), cavalcanti (1997), barroso (2002) and others; the methodology used was through a bibliographical source, having as instruments the bibliographical research, showing that sport and physical practices can and should be an important resource for the construction of a much more active and healthy life. initially, a literature review was undertaken to better understand the aging process, and how to age and stay healthy. Results: the results of this research aim to verify the relevance of sports practices for a healthier and more pleasurable life. conclusion: it is concluded that it is notorious that there is a small number of elderly people who adopt an active and sporting lifestyle and that it is necessary to stimulate and raise awareness about the importance of physical activities for body and mind.

Keywords: elderly; health; physical practices

${ }^{1}$ Bruno Freitas Santos Discente do curso de Mestrado em Educação da Anne Sullivan University Graduado em letras pela Faculdade de Tecnologia e Ciências (FTC BA) Professor da rede municipal de ensino (BA) Endereço: Av. João Ribeiro do Vale n`950 - Qd. 05.4720-000 - Remanso/BA, Brasil. e-mail: brunofreitas20017@.outloo.com 


\section{INTRODUÇ̃̃O}

O presente artigo traz uma relevante abordagem sobre o público da terceira idade e a relação das práticas esportivas para uma vida muito mais saudável e feliz. Tendo em vista, o sedentarismo tem sido um grande mal do século $X X I$, que tem levado muitos dos nossos idosos ao envelhecimento precoce e a morte prematura. Uma triste realidade da sociedade atual, que requer ações e intervenções precisas dentro dessa importante área.

O trabalho, ainda explana que uma vida ativa por meio do esporte e da grande variedade de atividades físicas é a chave para uma vida com qualidade e com saúde física e mental para os nossos idosos, principalmente para aqueles, que dentro das margens das doenças crônicas tais como hipertensão, diabetes, colesterol alto, triglicerídeos e tantos outros problemas dessa natureza, que tem sido os grandes vilões, matando todos os anos milhares de idosos em todo o mundo (GIANNINI, 1998).

Como foco central é feito uma abordagem sobre os muitos benéficos que uma vida esportiva pode trazer para a vida das pessoas da terceira idade, trazendo á tona a importância da autoestima, da autoconfiança e da inclusão social que o esporte é capaz de proporcionar (MCARDLE, $\mathrm{KATCH}, 1998)$.

Reflete ainda, que os nossos idosos precisam de uma atenção especializada, uma vez que eles são os alvos centrais do esquecimento e da ideia errônea de que não são mais uteis para uma vida ativa, dentre tantos outros preconceitos que os mesmos enfrentam diariamente na vida cotidiana. Dessa forma é imprescindível que haja um olhar prioritário, por parte de todos, principalmente a família e os órgãos de saúde, desenvolvendo ações de políticas públicas que sejam capazes de resgatar os nossos idosos do sedentarismo para uma vida mais ativa e feliz (BALTES e SILVENBERG 1995).

A justificativa que, impulsionou a elaboração desse artigo é conhecer melhor os benefícios e as vantagens que o esporte pode trazer para o público idoso, bem como envelhecer com a saúde física, social e mental do indivíduo. Pontos chaves que o esporte pode oferecer. A situação problema, que foi detectada nesse trabalho é combater os muitos preconceitos, que existe em cima da imagem da pessoa idosa, onde muito tem como inúteis e até mesmo usam termos pejorativos como os lixos da sociedade, sem nenhuma função frente à sociedade.
Dessa forma este artigo se encontra organizado o artigo se encontra organizado em três capítulos, que abrange a ideia central do idoso frente a uma vida esportiva. O primeiro capítulo faz uma breve contextualização da importância que o esporte pode exercer na vida do público da terceira idade; O segundo capítulo realiza uma pequena síntese sobre 0 envelhecimento humano como um ciclo natural da vida, mostrando que é possível envelhecer com qualidade e com saúde, usando as ferramentas oferecidas pelo esporte; $\mathrm{O}$ terceiro capítulo faz uma reapresentação da educação esportiva frente ao processo do envelhecimento como ponte para uma vida mais saudável. Por último, o texto mostra diferentes pontos de vista de teóricos convergentes e divergentes referentes a esse importante temático.

A educação esportiva é uma importante ponte de conexão para a construção de uma vida mais ativa e mais saudável para os nossos idosos. Então, o objetivo central é estimular a reflexão sobre a relevância, que as práticas esportivas podem trazer para o público da terceira idade, devolvendo um novo sentido para viver de forma mais prazerosa e ativa

\section{MÉTODOLOGIA}

Nesta obra cientifica de cunho bibliográfico, como afirma Cervo, Bervian e da Silva (2007, p.61), a pesquisa bibliográfica "constitui o procedimento básico para os estudos e pesquisas científicas". Essa fase é crucial para o desenvolvimento de uma obra cientifica, é também um ponto de partida que permite a coleta e a construção das informações que estão em pauta.

O método aqui utilizado é o bibliográfico, sendo o trabalho um artigo de revisão, que tem como principal característica "explorar por meio de diferentes autores a essência de um determinado assunto" (LAKATOS, 2007, p 107). Permitindo que fosse construído passo a passo o referencial teórico desse estudo.

Dessa forma, foram utilizadas pesquisas referentes à educação esportiva para o público da terceira idade, alertando para os benefícios que a mesma pode trazer. Para tanto, foram feitas consultas em sites científicos com os da Scielo demais plataformas virtuais com artigos, que apresentavam informações pertinentes, acerca dessa temática em seus vários aspectos. 


\section{RESULTADOS E DISCUSSÃO}

\section{INTRODUZINDO A TEMÁTICA}

Nos últimos anos muito se tem ouvido falar sobre a importância das práticas físicas. Com o objetivo de obter uma vida mais saudável, combatendo o sedentarismo que é um grave problema para a saúde, que requer intervenções sérias, emergenciais e precisas.

A novidade do momento é a atenção destinada para um público muito peculiar, os da terceira idade. Que na grande maioria das vezes ficam anônimos em muitos aspectos, depois de uma longa jornada de trabalho e depois de um grande acumulo de histórias e de experiências, ficam esquecidos em um determinado canto da sociedade e da família. Nesse sentido o esporte tem difundido por meio de suas muitas possibilidades, uma nova etapa para as pessoas idosas obterem uma vida muito mais estimulante, saudável e feliz.

O esporte e as práticas físicas apresentam uma infinidade de possibilidades para tornar a vida do ser humano mais ativo e mais saudável. E se tratando do público da terceira idade, isso surge como um instrumento de resgate de autoestima e de valorização do ser. Além do combate de uma série de doenças que são muito comuns nessa fase da vida (FERNANDES e SIQUEIRA, 2010).

Atividades físicas como caminhada, dança, corrida, musculação e a hidroginástica e tantas outras possibilidades são riquíssimas oportunidades para o público da terceira idade, que precisam tanto de um olhar afetuoso e carinhoso.

O esporte sem dúvida alguma é uma das melhores formas de se fazer atividade física, além de ter a função de saúde pública, trazendo inúmeros benefícios para a vida humana, independentemente da idade em que o ser humano se encontre. O esporte é um recurso capaz de trazer de volta a alegria de viver, o convívio social e a melhora quanto aos problemas de saúde. Algo que é muito comum nessa faixa etária. Que de acordo com a OMS Organização Mundial da Saúde a Terceira idade é a fase da vida que começa aos 60 anos nos países em desenvolvimento e aos 65 anos nos países desenvolvidos.

O envelhecimento do ser humano é uma fase que faz parte do ciclo da vida. E, é de suma importância compreender como acontece essa fase da vida humana. Um passo decisivo e importante para que sejam introduzidas as práticas esportivas de forma correta e eficiente. De acordo com Salgado (1999) e a (ONU) Organização das Nações Unidas (2005) só considera uma sociedade envelhecida quando esta alcança um índice de
$7 \%$ de idosos. $E$ de acordo com dados do IBGE, em 2015 a população brasileira com mais de 60 anos, somou 14,5 dos 160 milhões de brasileiros, aproximadamente $9,05 \%$. Nesse sentido há uma enorme necessidade de implantar e desenvolver políticas públicas voltadas para a saúde física e mental desse público, que sem sombra de dúvidas merece atenção e respeito por parte de todos.

Para entender o presente é necessário muitas vezes compreender o passado. E observando os dados históricos do censo de 1950, a expectativa de vida média era de 54,2 anos, um número preocupante. $\mathrm{Na}$ atualidade a expectativa de vida média é de 68,2 anos.

De acordo com os estudos de Salgado (1999) o Brasil por anos recebeu o estereótipo de país jovem. Por outro lado, isso não confere, pois de acordo com pesquisas recentes o Brasil é a nação do mundo com maior população idosa, perdendo apenas para China, Índia, Rússia e Japão. Infelizmente existe uma grande precariedade na saúde e na atenção aos idosos. Faltando emprego, saúde, habitação, lazer, respeito e atenção. Dessa forma governos, sociedade, comunidade, ONGs, empresas em todas as instâncias precisam priorizar uma atenção especial para esse público.

Os problemas que envolvem a população idosa são muitos e ao mesmo tempo preocupantes. Um desses problemas é apontado pelo IBGE (2000) é o desrespeito. O segundo problema é que muitos idosos brasileiros não possuem fonte uma de renda. Nesse sentido Barroso (2000) complementa que é preciso atentar para o terceiro problema que é a violência familiar. Uma triste realidade muito comum em muitos lares brasileiros.

Assim, para assegurar uma velhice com saúde é fundamental duas coisas: A qualidade de vida e a dignidade. E o esporte apresenta um leque de possibilidades para inserir esses dois importantes objetivos que são princípios bascos para uma vida melhor e mais feliz.

A conquista por melhores condições de vida tem sido ao longo dos anos um desafio para o homem. E com base nisso muitas interrogações e indagações surgem a respeito do segredo longevidade e como se faz para aumentar a expectativa de vida. A resposta é ainda muito simples: Uma boa alimentação, seguida da prática de atividades físicas.

O esporte sem sombras de duvidas continua sendo, um excelente recurso na promoção de uma vida saudável, capaz de apresentar inúmeras possibilidades de se viver bem e com qualidade. Muitos estudos têm 
demonstrado que, os idosos que praticam alguma prática esportiva têm ganhado massa e força muscular com treinamentos específicos para a sua idade e condições de saúde, que possuem. Para confirmar isso a Organização Mundial da Saúde (2000), afirma que cerca de $85 \%$ das pessoas idosas apresentam uma ou mais doenças ou problemas de saúde, tais como artrite, hipertensão arterial, doenças cardíacas, comprometimento da audição dentre outros. Tiveram melhorias significativas ao ingressar em um novo estilo de vida, onde o esporte tem agido com grandes efeitos na saúde como um todo.

Assim, surge a velha pergunta como envelhecer de forma saudável? A resposta vem por parte de cientistas do esporte, que esclarecem, que a realização de atividades físicas de forma regular, é ainda um dos grandes segredos para manter-se saudável na vida. $\mathrm{E}$ se tratando da terceira idade isso ganha mais peso, pois a população idosa é um público que merece prioridades, cuidados específicos e apoio especializado.

Os benefícios das práticas físicas são inquestionáveis, além de fazer bem para o corpo e, também, para a cabeça. É uma ferramenta usada na medicina do esporte e da psicologia para resgatar a autoestima, o prazer e a motivação. Três pontos interessantes que a falta dos mesmos tem levado um índice crescente de pessoas ao mal do século a depressão. Que de acordo com dados OMS (1998) essa doença afeta $4,4 \%$ da população mundial e $5,8 \%$ dos brasileiros. Tais dados são preocupantes ao falar de saúde pública, sendo necessárias as ações e intervenções precisas.

A prática de uma atividade física é retorno garantido para a saúde do sujeito. E se tratando de pessoas idosas, há enormes vantagens para aqueles, que exercem alguma prática esportiva, tais como a melhoraria significativa da coordenação motora, o estágio de relaxamento, o contato com outras pessoas, a recuperação da confiança em si mesmo dentre tantos outros.

As danças são excelentes recursos como para manter a saúde física e saúde mental. De acordo com um estudo feito pelo Albert Einstein (1994) College of Medicine, em Nova York, foi constatado o obvio. A dança como o tango, a dança de salão, flamenga, o ventre, moderna, clássica é uma terapia para a vida da pessoa idosa. Pois de acordo com o referido estudo, o cérebro é uma máquina surpreendente quando Ihe é dada a motivação correta. Nesse caso a dança como uma prática esportiva, tem o poder de prevenir a doença de Alzheimer e a perda de memória. Assim, é preciso articular ações e intervenções de saúde pública que estimulem os idosos a realizar atividades físicas na forma de danças.

De acordo com o IBGE (2015) o Brasil possui 22,3 milhões de pessoas com idade acima de 60 anos. O número de idosos no Brasil e no mundo cresce com a taxa de doenças crônicas e, inclusive o Alzheimer. A partir dos 65 anos, o risco de desenvolvimento de doenças crônicas é alto. Assim, é necessário que os órgãos de saúde desenvolvam mais e mais ações de políticas públicas, que englobem a dança e o esporte como um recurso de combate e de prevenção dessas doenças. Como confirma estudos pessoas que praticam alguma atividade física tem o dobro de chances de não desenvolver doenças, tais como o Alzheimer e tantas outras. Porque o sedentarismo é um mal silencioso. E de acordo com dados do IBGE (2015) a maioria dos brasileiros possui uma vida é sedentária. $E$ isso ocorre a partir da adolescência, passando pela juventude, fase adulta e pôr fim a velhice. E a referida pesquisa ainda aponta que 0 sedentarismo atinge $70 \%$ dos brasileiros e mata cerca de 300 mil brasileiros por ano. Esses dados são alarmantes, sendo necessárias ações e intervenções que venham amenizar esses entraves.

$E$ em concordância a tudo isso a Pesquisa Nacional por Amostra de Domicílios PNAD (2015), aponta que $62,1 \%$ dos brasileiros com 15 anos ou mais não praticaram qualquer esporte ou atividade física. Organização mundial de saúde (OMS) (1998) isso revela que falta investimentos e estimulo por parte dos órgãos responsáveis de saúde. Então, Ministério da Saúde, ONGs, empresas e toda a sociedade civil precisa se mobilizar em prol de uma vida mais saudável, em especial o público da terceira idade, que é alvo central, carente de cuidados e de atenção. Assim a OMS definiu algumas recomendações sobre atividades físicas, dando a seguinte recomendação que crianças, adolescentes, jovens, adultos e idosos devem praticar pelo menos 60 minutos de atividade física moderada a intensa por dia. $E$ aqueles que não obedecem, tais recomendações ficam as margens do sedentarismo, sendo alvo fácil para tantas doenças causadas pelo sedentarismo.

O universo do esporte é riquíssimo em diferentes opções, e de acordo com Organização das Nações Unidas (ONU) dedicou o ano de 1999 como o ano Internacional dos Idosos, mostrando muitos benefícios que à terceira idade pode e deve 
desfrutar. Listando algumas práticas esportivas que são simples e acessíveis para todos.

Por exemplo, a natação ou hidroginástica trazem benefícios incalculáveis tais como o fortalecimento dos músculos e a melhoria do sistema respiratório. Atividades aquáticas são classificadas como exercício aeróbico que protege as articulações, e se tratando do público idoso isso é totalmente benéfico para a sua saúde física e mental.

Outra excelente sugestão para envelhecer com saúde é a realização de caminhada ou corrida, que aconteçam dentro de um intervalo de tempo, que seja de 30 minutos. Os benefícios surgem no combate de problemas cardiovasculares, melhora a respiração e fortalece os músculos.

Outra proposta bem simples e barata é a prática do ciclismo. A simples atividade de andar de bicicleta é uma atividade prazerosa e é muito útil para todos os públicos das diferentes idades. E se tratando dos idosos os benefícios vem na forma de fortalecimento dos músculos do quadril e das pernas.

Dessa forma os exercícios funcionam com um tratamento preventivo para evitar o surgimento de várias doenças, principalmente àquelas que são muito comuns nos músculos, na circulação sanguínea e na respiração. $E$, já foi constatado que por meio da realização de atividades físicas o índice de acidentes em idosos é reduzido. E outra importante conquista é que por meio da realização de atividades os idosos podem aumentar expectativa de vida, pois 0 sedentarismo é uma das principais causas que levam a morte (FRANCHI e MONTENEGRO, 2005).

\section{O ENVELHECIMENTO: DESTRINCHANDO A TEMÁTICA}

A sociedade de muitas culturas de forma equivocada carrega sobre si de uma imagem pejorativa, quando se trata do envelhecimento. Isso ocorre de forma errônea, pois é nessa fase em que o homem e a mulher se tornam mais confiante, experiente e autônomo em muitos aspectos.

Existe a ideia de forma destorcida, que o envelhecimento é sinônimo de fragilidade física e um conjunto de doença. Por outro lado, essas ideias caem por terra, pois se tem visto inúmeros exemplos de pessoas idosas, superando expectativas e rompendo barreiras e tabus que foram construídos ao longo dos anos.

$\mathrm{Na}$ visão de Guedes (2000) muitos idosos têm provado para si mesmo, de forma eficiente que são indivíduos capazes produzir, trabalhar e contribuir em diversas áreas e diferentes aspectos. Tem sido mostrado por meio de estudos, que 0 idoso independentemente do processo de envelhecimento é ainda um sujeito ativo, capaz de realizar inúmeras atividades dentro e fora do ceio familiar, vivendo uma vida totalmente produtiva e saudável.

A sociedade de forma preconceituosa ou não, vive criando termos para classificar as pessoas e a faixa etária de cada um a velhice data dos anos 60, nos anos 70. De acordo com Neri (1991) o envelhecimento é um processo evolutivo natural do sujeito, sendo necessário enxergar o que tem de melhor em cada uma das fases da vida. Os referidos autores trazem uma mensagem muito poética e realista... O envelhecimento não deve ser encarado como um prenúncio de morte, pois a morte não é privilégio só da velhice, ela pertence a todas as fases da vida. $O$ envelhecimento é uma fase da vida, rica em possibilidades e em oportunidades. Mesmo em meio ao vigor físico reduzido. Esse público merece respeito e valorização.

Na visão de Marques Filho (2000) os idosos representam uma contribuição importante e fundamental para a preparação das gerações futuras. $E$, isso é muito real, pois eles têm muito a oferecer para aconselhar, exortar e compartilhar junto a todas as experiências acumuladas durante toda uma vida. Lamentavelmente existe muito desprezo e desrespeito por parte de alguns integrantes da própria família ao lançarem muitos desses idosos em casa de apoio ou em asilo. Na visão de Neri (1991) o envelhecimento é definido como uma experiência pessoal e individual. A mesma possui múltiplos significados: maturidade, experiência individual, interindividual, grupal e sociocultural.

A idade cronológica não mede potencial nenhum, como é a visão errônea de muitos que medem resistência. De acordo com Organização Mundial da Saúde (2005) é possível ser saudável, independentemente da idade. E para ser saudável são necessários alguns requisitos básicos, tais como: uma boa alimentação, dormir cedo para garantir um bom sono e seguir diariamente a realização de práticas esportivas e do exercício físico.

$$
\text { Para muitas culturas } 0
$$
envelhecimento é um processo importante e não o motivo de desrespeito e de vergonha. Como se tem visto em muitos países que chegam a dizer que os idosos são as sanguessugas da previdência social. Pelo contrário, envelhecer é acumular experiências, é um alto enriquecimento na vida. E a prática 
do esporte apresenta um leque de possibilidades para somar pontos positivos dentro desse campo de experiências e de possibilidades.

Ao falar de envelhecimento, logo somos direcionados para as características que surgem dentro dessa faixa etária. Nesse sentido Marques Filho (2000) fala de dois importantes tipos de envelhecimento. O primeiro 0 teórico classifica como envelhecimento normal, que de forma simplificada significa aquele ditado para cada espécie. $O$ segundo é 0 envelhecimento Patológico, que de forma resumida é aquele no qual as doenças interferem direta ou indiretamente na qualidade de vida e na aparência do sujeito. E o esporte vem como uma ação preventiva e reparativa dentro do contexto do segundo envelhecimento, o patológico. Porque já foi comprovado por meio de várias pesquisas e estudos científicos que, quem pratica alguma atividade física, possui um aspecto mais jovial, mais energia, disposição e um brilho no olhar diferente dos demais, onde é perceptível para todos em sua volta.

O envelhecimento é um processo natural e inevitável para todos. Porém na visão de Simões (1994) é possível sim conquistar um envelhecimento sadio, tanto fisicamente como mentalmente. $E$, isso é possível por meio da alimentação saudável acompanhada da prática continua e regular de atividades físicas. priorizada uma atenção especial ao envelhecimento prematuro. Que cada vez mais é comum no público da terceira idade e até mesmo em outras faixas etárias. Esse envelhecimento precoce é uma doença extremamente perigosa, sendo necessária a identificação do diagnóstico para a iniciação do tratamento com profissionais especializados. Esse problema atinge 0 aspecto físico e cognitivo do sujeito. Assim, o esporte e as práticas físicas podem funcionar como um excelente recurso auxiliador no tratamento dessa doença.

Simões (1994) em seus estudos também fala que a realização contínua e regular de atividades físicas na vida dos idosos é de suma importância. Porque, além de melhorar a coordenação motora, retardar o envelhecimento combater a alta irritabilidade etc. E, por último, ajuda na preservação da memória. Pois, junto com o envelhecimento, surgem as perdas consideráveis da memória. Para tanto é imprescindível, que haja mais ações voltadas para as políticas públicas de saúde, que priorizem todas essas necessidades, tanto físicas, como emocionais. Que a cada ano são apresentadas por meio de pesquisas estatísticas.

Salgado (1982) traz uma importante explicação sobre o envelhecimento físico. Que aparentemente se apresenta como a perda da força e da forma muscular, acompanhada de uma imagem pesada e gasta ao corpo. A realização de atividades físicas vem como uma possibilidade de se saborear na fonte de juventude. $E$ se tratando desse importante público, isso se torna muito relevante, porque qualidade de vida é algo necessário para todos. O referido autor, ainda traz o benefício do retardamento do envelhecimento mental. Porque o cérebro de quem prática algum esporte tem outro tom e outro ritmo de funcionamento.

Wagorn (1993) traz uma importante discussão sobre o rejuvenescimento físico, mental e emocional do sujeito. O referido autor explica, que as práticas esportivas são tão relevantes que conseguem alcançar a alta estima do indivíduo, mudando a visão de mundo acerca de si mesmo, acerca do outro e acerca do mundo a sua volta. O esporte vai tão além dentro de seus efeitos positivos que é capaz de modificar a nossa aparência, os sentimentos que sentimos no íntimo do ser humano. Assim, o esporte pode propiciar inúmeros benefícios, tais como uma ponte para superar as frustrações, que são acumuladas ao decorrer da vida fortalecendo o lado emocional e espiritual do sujeito, e isso é algo muito positivo.

Os idosos em especial são um público carente de atenção e de afeto e precisam de atenção mais do que prioritária. $\mathrm{E}$ um ponto muito relevante é abordado por Canoas (1985) ao falar do estágio de aborrecimento e de melancolia que é comum na vida das pessoas da terceira idade, e que gera um desequilíbrio social e emocional do sujeito. Esse problema é cada vez mais comum. E a apresentação das práticas esportivas nessa idade é uma riquíssima oportunidade para melhorar as relações interpessoais, 0 aspecto psíquico e o biológico. Marques Filho, (2000) comenta que é natural na terceira idade acontecer as diferentes alterações morfológicas e funcionais do corpo humano, gerando um declínio nos movimentos, que se tornam cada vez mais lentos e ocorre uma perda de agilidade e de habilidades. Que anteriormente o indivíduo conseguia desenvolver de forma mais rápida e precisa. O esporte e a realização de suas práticas vêm combater a esse problema muito comum. Devolvendo agilidade, habilidades e 
resistência. Dentre tantos outros aspectos que aqui não foram citados.

Dando continuidade ao pensamento anterior, o preconceito contra a pessoa idosa é outro desafio enfrentando diariamente por essa classe de pessoas como aponta Simões (1994), a "Palavra Velho" é um termo frequentemente usado de forma pejorativa e ofensiva. A própria mídia e a sociedade no geral criam essas expressões, como se a pessoa idosa fosse com o tempo, se deteriorando e perdendo capacidades e habilidades.

$E$, infelizmente isso é algo que magoa e fere as pessoas, mas na realidade esse tipo de preconceito precisa ser combatido. Porque hoje se tem visto pessoas idosas com um estilo de vida saudável e esportivo. É inegável que existe às perdas de habilidades e de determinadas capacidades ao longo do tempo. Por outro lado, existem também os acúmulos e ganhos de experiências e de maturidade. Simões (1994) em seus estudos mostra que muitos idosos tem sido verdadeiros heróis ao vencer as perdas ao longo dos anos no corpo físico, a falsa imagem de inutilidade para a família e para a sociedade. Conquistando certa qualidade de vida e exercendo certas profissões depois da aposentadoria.

Salgado (1982) volta a trazer à tona, que o envelhecimento não é algo pejorativo e ofensivo como muitos acreditam. Envelhecer é algo significante e possuem vários privilégios dentro de determinadas culturas, como por exemplo, a chinesa e a japonesa. Que enxergam e valorizam seu público da terceira idade como joias da maturidade e da experiência. Considerando-as como as mais sábias e lhes conferindo posição honrosa. $E$ relacionando com 0 esporte, isso só é dado continuidade, pois o esporte tem esse poder de inclusão de pessoas, independentemente da faixa etária que ela tenha. Dando e reconhecendo o seu real valor dentro da comunidade e da sociedade.

Sevcenko (1991) revela por meio de seus estudos, que o preconceito contra os idosos é algo a ser combatido e é algo muito real e comum. O referido autor acrescenta que existem civilizações que o envelhecimento é símbolo de dignidade. Lamentavelmente existem outras culturas que são preconceituosos e possuem uma visão distorcida e que são carregadas de repúdio. Essa palavra repúdio é muito forte, e tal preconceito precisa ser combatido, e o esporte vem como um instrumento útil nesse árduo combate. Assim, logo somos direcionados a fala de Cavalcanti (1997), que explica que a juventude é uma fase transitória e que a velhice é a fase definitiva.

As consequências do envelhecimento são inevitáveis, sendo elas as consequências físicas, emocionais, sociais e psicológicas. No entanto pelo viés do esporte muitas dessas dificuldades podem ser superadas e amenizadas com sucesso. Porque o esporte vem, como uma bola capaz de trilhar, todos esses obstáculos encontrados pelo caminho, ou seja, é possível envelhecer com saúde e com qualidade. E para confirmar essa ideia Antunes (2006) usa as palavras de Rousseau que diz que a velhice é o momento de praticar a sabedoria outrora conquistada, e inserir uma vida esportiva nessa fase da vida é um exemplo claro de sabedoria.

\section{COMO TER UMA VELHICE SAUDÁVEL COM AJUDA DO ESPORTE.}

Ribeiro (1999) diz que a resposta está alicerçada primeiramente na aceitação de que o corpo humano passa por várias mudanças e que é necessário aproveitar o que a vida tem de melhor. Os referidos autores ainda fazem uma seguinte lista: Alimentação correta; manter a higiene corporal; não fumar ou beber; dormir o suficiente e a realização continua de exercícios físicos. Tais seguimentos sendo cumpridos trarão as condições básicas para uma vida mais e mais saudável. Simões (1994) faz uma importante lista dos benefícios trazidos pelas práticas esportivas. O primeiro deles é o benefício físico, redução dos riscos de problemas crônicos coronarianos, melhora e aumento da resistência física.

O segundo dos benefícios são os emocionais, tais como ajuda na manutenção do equilíbrio emocional, diminuição da ansiedade que gera o estresse que tem sido a doença do século. O terceiro benefício segundo Simões (1994) é o benefício social, que auxilia na melhora das relações sociais através da integração social e outros. E o quarto e último são os benefícios psicológicos, que exercem uma relevância no aumento da autoconfiança e autoestima; dessa forma é necessário que haja o desenvolvimento de ações e intervenções de políticas públicas na área da saúde dos idosos, onde haja cada vez mais ampliação de todo esse importante trabalho, que é o esporte para a terceira idade.

Nos estudos de Forti (1999) as práticas esportivas funcionam como um procedimento eficaz que pode ser usado para retardar o processo de envelhecimento. Os referidos autores ainda acrescentam que outro importante benefício é a ação preventiva no 
combate as doenças comuns à faixa etária para aqueles que vivem dentro de um quadro sedentário. O referido autor ainda mostra que realização de atividade física de forma regular e continua pode reduzir em $51 \%$ o risco de morte natural. É importante ressaltar que 0 uma vida sedentária é um fator de risco que requer serias e emergenciais intervenções. Dessa forma Guedes (2000) deixa um lembrete que toda e qualquer atividade física, requer a presença de um profissional qualificado dentro da área esportiva, com o intuito de evitar prejuízos e malefícios à saúde do idoso. E como reforço de todo esse questionamento Balbinotti (2003) diz que é preciso aprender 0 segredo de saber envelhecer, e tal segredo está configurado em uma vida ativa por meio das práticas esportivas.

Os cuidados ao praticar qualquer atividade física são imprescindíveis. Porque o segredo de uma atividade física saudável e livre de qualquer risco é sempre as medidas preventivas. O trabalho quando é desenvolvido com consciência e com cautela é mais produtivo e benéfico e automaticamente não trará prejuízos à saúde do sujeito.

Os esportes para a público da terceira Idade é mais que um remédio é mais que uma terapia. É uma ação preventiva para evitar inúmeras doenças que são resultadas de uma vida sedentária e que têm levado muitos sujeitos a morte. Dessa forma somos direcionados para os estudos de Appell \& Mata (1998) onde afirmam que o esporte é uma ferramenta útil para retardar o processo de envelhecimento, permite uma melhor qualidade de vida de forma que deixam as pessoas mais ativas. E o melhor que os autores apontam com base em estudos científicos, tem o efeito de prolongar os dias de vida. Tudo isso é muito positivo e muito aceitável, então é necessário que haja cada vez mais o estimulo as práticas esportivas para que tenhamos uma sociedade idosa mais enérgica e mais saudável.

Prado (2000) em seus estudos trata o mundo dos esportes como uma linguagem universal. $E$, isso é uma verdade, pois independentemente de onde quer que estejamos o esporte rompe fronteiras de territorialidade e de idiomas. Dessa forma essa importante linguagem deve ser sempre trabalhada e estimulada em todas as instâncias. É através das modalidades esportivas que se encontram a possibilidade de se trabalhar e de se desenvolver os valores, a competitividade, a superação dentre tantos outros aspectos. O significado que 0 esporte tem é tão amplo e profundo que Silva
(2000) define o mesmo como um fenômeno sociocultural.

O excesso na realização das atividades físicas é um tópico a ser respeitado. Porque tudo em excesso é prejudicial. Marques Filho (1999) expõe que cuidados são necessários para se evitar danos e lesões ao corpo. Respeitar os limites do corpo é sempre bem-vindo. A intensidade, o ritmo, a velocidade são sempre muito individuais e varia de individuo para indivíduo. Quando esses requisitos básicos não são respeitados surge o abandono. Então, é necessário um olhar prioritário para essas questões tão básicas e necessárias. Marques Filho (1999) acrescenta em sua fala que o esporte não é instrumento para se superar dificuldades, desafios, tabus e a idade cronológica.

Como confirma o Dr. Lair Ribeiro, um grande referencial no mundo das pesquisas científicas na área da saúde humana, em uma das suas obras "Envelhecer, sem ficar velho". Nessa obra o médico dá ênfase para dois pontos primordiais. Primeiro é dado ênfase para a alimentação usando a frase de Hipócrates: "Deixe seu alimento ser o seu remédio e o seu remédio ser o seu alimento". $E$ em segundo momento é dado ênfase para a realização dos exercícios físicos que de acordo com a Organização Mundial da Saúde (2005) o sedentarismo é uma das principais causas de morte no mundo atual. E de acordo com a Organização Mundial da Saúde o organismo humano precisa gastar energia, estimular as células e os músculos. $E$, isso só é possível por meio das práticas esportivas.

\section{CONCLUSÃO}

Levando em consideração tudo que aqui foi exposto, podemos verificar que a prática de esportes na terceira idade é necessária para uma vida longa, saudável e feliz. O esporte na Terceira Idade é um caminho excelente para vencer a fragilidade física à superação de inúmeras doenças crônicas. Ficou comprovado que o esporte na Terceira Idade possui inúmeras funções, dentre as quais aparece à socialização, a manutenção do equilíbrio físico e mental.

A qualidade de vida é um o objetivo central da grande maioria das pessoas. E, tal qualidade de vida se torna mais concreta, quando há a prática continua de alguma atividade física, seja a ginástica, a caminhada ou a musculação.

Atividade física para pessoas idosas é cercada ainda de muitos preconceitos sociais. No entanto é necessário lutar contra essas ações de total desinformação e ignorância que se tem construído em cima das 
pessoas da terceira idade. $O$ fator fundamental do esporte aqui é propiciar uma vida mais saudável tanto física como mentalmente. $\mathrm{E}$ isso é totalmente possível quando existe a prática continua de exercícios físicos sob a orientação de um bom profissional e a alimentação adequada.

O esporte para o público da terceira idade não é desenvolvido da mesma forma que para um público juvenil. É necessário um trabalho com uma maior conscientização, pois se trata de um público peculiar, e que requer atenção prioritária.

Lembrando que os benéficos são garantidos, desde que seja praticado de forma correta e vem na forma de um bem-estar físico, mental que em outras palavras é a saúde. O melhoramento no convívio social e o mais importante à alegria de viver, a autoestima que só o esporte é capaz de resgatar.

É importante ressaltar que grande parte dos idosos, que optaram por uma vida esportiva, obtiveram resultados significativos, tais como melhoras físicas como maior disposição, mais energia para realizar as demais atividades do dia a dia.

Assim, diante das novas possibilidades, que aqui foram apresentadas, surge a necessidade de maiores investimentos e de maior incentivo para que cada vez mais cresça o número de idosos que estejam enquadrados dentro de uma vida mais ativa e mais saudável, sob o viés do esporte.
Diante inevitável que é o envelhecimento, as práticas esportivas vêm como uma ação reparativa e de retardamento frente ao envelhecimento humano. Ressaltando que é preciso cautela em todos os sentidos, para que sejam colhidos apenas os benefícios do esporte. Tendo em vista, que o universo esportivo oferece um grande leque de possibilidade para construir gradativamente uma saúde física, mental e social do sujeito. Ressaltando também, que existe uma grande deficiência no requisito projetos de leis e a construção de políticas públicas, na área da saúde que contemple os idosos.

Por fim, a educação esportiva para o público da terceira idade é um novo aprendizado capaz de instruir, ensinar, levar a um universo de maiores possibilidades, onde o próprio idoso irá se enxergar com outros olhos, vendo que é capaz e que há um potencial a ser trabalhado e explorado.

Por último, em resposta ao objetivo inicial e a situação problema aqui proposta, conclui-se que o objetivo foi atingido, pois a partir dessa discussão foi possível refletir sobre a temática, desconstruindo a visão preconceituosa de que o idoso não pode ter uma vida atlética, ativa e esportiva. Como sugestão, indica-se que novos estudos sejam realizados dentro desse importante temático, para que sejam aprofundados outros aspectos que estão contextualizados com a mesma.

\section{REFERÊNCIAS}

ANTUNES, V. L. O Conceito de Soberania em Jean-Jacques Rousseau. Dissertação (Mestrado em Filosofia). Programa de Pós-graduação em Filosofia. Universidade Federal de Santa Catarina. Florianópolis, 2006.

AGUIRRE, J. A. C. El Legado de Hipocrates. Buenos Aires, El Ateneo, 1938.

APPELL, H. J. \& MOTA, J. Desporto e Envelhecimento. Revista Terceira Idade. Editora SESC, São Paulo/SP, 1998.

BALBINOTTI, H. O segredo de saber envelhecer. Revista Viver Psicologia, N¹23, ano XI,abril de 2003, p.16-18.

BARROSO, M. Donos do seu nariz. Revista E. ed. $n^{\circ} 42$. Disponível em:<http://sesc. uol.com. br/sesc/revista/e/index. htm> "Acesso em: 15/07/2018".

BALTES, M. M.; SILVENBERG, S. A dinâmica dependência-autonomia no curso de vida. In: Neri AL. Psicologia do envelhecimento: temas selecionados na perspectiva do curso de vida. Campinas. Papirus, 1995 (Coleção Viva Idade).

CAVALCANTI, C. S. Caminhos da vida. Recife: Bagaço,1997.

CANÔAS, A S. A Condição Humana do Velho. Cortez, 2a ed., São Paulo/SP,1985.

CERVO, A. L.; BERVIAN, P. A.; SILVA, R. Metodologia científica. 6. ed. São Paulo: Pearson Prentice Hall, 2007.

EINSTEIN A., Carta a M. Born de 4 de dez. 1926. In: SCHILPP, P. A. (org.). Albert

Einstein: Escritos da maturidade. Tradução M. L. X. A. Borges. Rio de Janeiro: Nova Fronteira, 1994.

FERNANDES, W. R.; SIQUEIRA, V. H. F. Educação em saúde da pessoa idosa em discursos e práticas: atividade física como sinônimo de saúde. Interface (Botucatu). 2010; 14(33):371385.DOI:http://dx.doi.org/10.1590/S1414-32832010000200011. 
FRANCHI K. M. B.; MONTENEGRO, R. M. Atividade física: uma necessidade para a boa saúde na terceira idade. Revista Brasileira em Promoção da Saúde, v. 18, n. 3, p. 152-156, 2005.

FORTI, V. A M. Influência do Treinamento Físico Aeróbico sobre as respostas cardiovasculares e respiratórias em mulheres na menopausa com e sem terapia de reposição hormonal. Tese (Doutorado). Faculdade de Educação Física /UNICAMP. Campinas, 1999.

GUEDES, M. Mundo Ativo. Revista E. ed. n'13. Disponível em:<http://sesc.uol.com. br/sesc/rev1sta/e/index. htm> "Acesso em: 15/07/2018".

GIANNINI SD. Aterosclerose/Dislipidemias, Clínica e Terapêutica: Fundamentos Práticos. São Paulo: BG Cultural, 1998.

LAKATOS, E. M.; MARCONI, M. A. Fundamentos de metodologia científica. 5.ed. São Paulo: Atlas, 2003.

MARQUES FILHO, E. Atividades Físico-Esportivas Para Terceira Idade.SESC, Campinas/SP, 2000.Momento Delicado. Revista E. ed. em: <http: I /se se. uol I. com. br/sesc/revista/e/i ndex. htm>acesso15/07/2018".

MCARDLE, W. D.; KATCH, F I.; KATCH, V. L. Fisiologia do Exercício: Energia, Nutrição e Desempenho Humano. 4ª ed. Rio de Janeiro: Guanabara Koogan, 1998.

NERI, A. L. Envelhecer num pais de jovens: significados de velho e velhice

segundo brasileiros não idosos. Editora da Unicamp, Campinas/SP, 1991.

OMS. Conferência Internacional sobre Cuidados Primários de Saúde: Declaração de Alma-Ata, 1978. Brasília, DF: Ministério da Saúde, 2004.

OMS. Relatório mundial de saúde, 2006: trabalhando juntos pela saúde. Brasília, DF: Ministério da Saúde, OMS, 2007. Disponível em: <http://www.opas.org.br/mostrantp.cfm?codigodest=586>. Acesso em: 4 mar. 2018.

ORGANIZAÇÃO MUNDIAL DA SAÚDE. Envelhecimento ativo: uma política de saúde. Brasília; DF: Organização Pan-Americana de Saúde, 2005.

PESQUISA nacional de saúde 2013: percepção do estado dês saúde, estilos de vida e doenças crônicas: Brasil, grandes regiões e unidades da federação. Rio de Janeiro: IBGE, 2014. 180 p.Acompanha 1 CD-ROM. Disponível em: <http://www.ibge.gov.br/

home/estatistica/populacao/pns/2013/default.shtm>. Acesso em: abr. 2018.

PESQUISA nacional por amostra de domicílios: síntese de indicadores 2015. Rio de Janeiro: IBGE, 2016. 101 p. Disponível em: <http://www.ibge.gov.br/home/estatistica/populacao/trabalhoerendimento/ pnad2015/default_sintese.shtm>. Acesso em: abr. 2018.

PRADO, A. C. M. Uma boa jogada. Revista E. ed. n'42. Disponível em:<http//sec uol. com. br/sesc/revista/e/index.htm> "Acesso em: 15/07/2000".

RELATÓRIO executivo da pesquisa. In: DIAGNÓSTICO nacional do esporte: a prática do esporte no Brasil. Brasília, DF: Ministério do Esporte, 2015. Disponível em: <http://www.esporte.gov.br/diesporte/7.php>. Acesso em: maio 2017.

RIBEIRO, M. G. C. Idosos em Movimento: Mantendo a Autonomia: Evolução e Referencial teórico. Editora EUERJ, UNATI, Rio de Janeiro/RJ, 1995.

SALGADO, M. A. Velhice, uma nova questão social. Revista Terceira Idade. $2^{\mathrm{a}}$ Ed. SESC-CETI, São Paulo/SP, 1982.

SALGADO, M. A. Por uma Pedagogia do Adequado Envelhecimento. Revista A Terceira Idade. Editora SESC, Ano X, n. 16, maio, São Paulo/SP, 1999.

SEVCENKO, N. O Envelhecimento e o mistério da passagem do tempo.Revista A Terceira Idade. Editora SESC, Ano IV, n. 4, julho, São Paulo/SP, 1991.

SILVA, E. C. Século 20, o século dos esportes. Revista E. ed. N"12.Disponível em:< http://sesc.uol.com br/sesc/rev1sta/e/1ndex.htm> "Acesso em:15/07/2018".

SIMÕES, R. Corporeidade e Terceira Idade: a marginalização do corpo idoso., 2' ed. Editora Unimep, Piracicaba/SP, 1994.Terceira Idade em forma. Revista E. Ed. N. 15. Disponível em:<httQ:I/sesc.uol com_br/sesc/revista/e/index.htm> "Acesso em: 15/07/2018".

WAGORN, Y. et al. Manual de Ginástica e bem estar para a Terceira Idade: para uma velhice feliz e saudável. Editora Marco Zero. São Paulo/SP,1993. 